\title{
EL PROCESO DE CONSOLIDACIÓN DE LA UNIVERSIDAD PEDAGÓGICA NACIONAL FEMENINA EN EL MARCO DE LA CONTRA-REFORMA EDUCATIVA DE LOS AÑOS 50
}

\author{
Juan Carlos Garzón Barreto*
}

\begin{abstract}
Resumen
Los años 50 representaron un viraje radical en la política educativa colombiana, particularmente en la formación de docentes; en 1952, el gobierno nacional toma la decisión de cambiar la denominación de la Escuela Normal Superior y dividirla en dos instituciones por sexos: los hombres son enviados a la Normal de Varones de Tunja y las mujeres al Instituto Pedagógico Nacional para señoritas de Bogotá, dando lugar a un intrincado proceso de aplicación de las nuevas políticas de formación de docentes y con el apoyo de una Misión Alemana se constituye la Escuela Normal Universitaria Femenina, que para el año 1955 se convertiría en la Universidad Pedagógica Nacional Femenina, institución que funciona con tal nombre basta 1962, año en el cual se establece su carácter mixto y su denominación actual de Universidad Pedagógica Nacional.
\end{abstract}

Palabras claves: educadores - pedagógica - reforma - historia -femenina

\section{Summar}

Process of the consolidation of the Universidad Pedagógica Nacional Femenina in to the frame of the educational contrareform of the years 50 's.

The 50's represented a radical change in the colombian educational policy, specially in the teachers formation. On 1952 the national goverment takes the decision of change the name of the Escuela Normal Superior and devides in two institutions by sex: men were send to the Normal de Varones de Tunja and women to the Instituto Pedagógico Nacional for young ladies in Bogotá, causing an intricate process of aplication of the new polices in teacher formation and with the help of one German Mision was establish the Escuela Normal Universitaria Femenina that on 1955 had converted in the Universidad Pedagógica Nacional Femenina, institution that funtioned with that name until 1962 year in wich is establish her mixed character and her present name of Universidad Pedagógica Nacional.

\footnotetext{
* Presidente de la Asociación de Egresados de la Universidad Pedagógica Nacional. Estudiante de la Especialización en Pedagogía de la U.P.N. 


\section{Introducción}

La historia de la primera mitad del presente siglo en Colombia, da cuenta del período comprendido entre 1930 y 1946, conocido como "La República Liberal", lapso en el cual, representantes del liberalismo colombiano ejercieron —entre otras cosas- la Presidencia de la República.

En el período en cuestión, transitaron por el escenario nacional una serie de reformas políticas y constitucionales que contribuirían a encender el ambiente de las posturas ideológicas, donde los protagonistas de primera línea serian la iglesia y los partidos políticos tradicionales.

Este debate tomó particular fuerza en el gobierno de Alfonso López Pumarejo, quien propuso la reforma constitucional indicando que:

El liberalismo creía honradamente en la necesidad de reformar la carta del 86. (...) en el curso del debate pudo confirmarse que jurisconsultos liberales de dentro y fuera del Congreso veían con temor una constitución que no tuviera las mismas bases tradicionales. (...) El Congreso suprimió algunos artículos de la carta fundamental para obtener la independencia del poder civil en relación con el eclesiástico. ${ }^{1}$

Alfredo Molano considera que para este período el Partido Liberal fue ganando un amplio respaldo que le permitió: ". .emprender una reforma de las instituciones del Estado, de las relaciones entre el poder civil y la iglesia, la estructura de la tierra y el sistema educativo. Era la revolución en marcha. ${ }^{2}$

La polémica ${ }^{3}$ encontraba su punto central en el hecho de que los artículos a reformar en el Estatuto constitucional de 1886, eran aquellos que dejaban la orientación y parte del control de la educación pública en manos de la iglesia, consideración sobre la cual se firmó el Concordato de 1887.

En el plano de las actividades educativas adelantadas durante la República liberal podemos señalar: la unificación de la Escuela rural y urbana, el ordenamiento de que en ninguna institución educativa se le podía impedir el ingreso a los llamados hijos ilegítimos y el establecimiento y obligatoriedad de la función de suprema inspección y vigilancia de la educación por parte del Estado.

En el terreno de la formación de los educadores, el gobierno de López Pumarejo expidió el decreto 1917 del 25 de octubre de 1935, mediante el cual ordenó concentrar en una sola institución las Facultades de Educación de la Universidad Nacional, la de mujeres adscrita al Instituto Pedagógico Nacional y la de Varones que venía funcionando en la ciudad de Tunja. Posteriormente, la Ley 39 del 21 de febrero de 1936, cambió el nombre de la Facultad de Educación por el de Escuela Normal Superior y dispuso que esta institución quedaría bajo la dirección directa del gobierno nacional.

\footnotetext{
1 Jaime Jaramillo Uribe. Antología del Pensamiento político colombiano. Banco de la República. Bogotá. Tomo 2. Pág. 241.

${ }^{2}$ Alfredo Molano. César Vera. La evolución de la política educativa durante el siglo XX. CIUP-UPN. 1982. Pág. 61.

${ }^{3}$ Un detallado estudio del proceso que se llevó a cabo en el Congreso de la República con motivo del trámite de estas reformas. fue elaborado por el historiador Jorge Rafael Mora Forero. Los conflictos educativos entre la iglesia y el Estado. Primer gobierno de López Pumarejo. Edit. Universidad Antonio Nariño. Santafé de Bogotá. 1996. 
El breve examen de algunas de las características de la institución y de las circunstancias en que tiene lugar la creación de la Escuela Normal Superior, resulta ser un ejercicio de gran utilidad para rastrear algunas de las causas de su disolución. Precisemos tres elementos: La Normal Superior surge tras la desaparición de la Facultad de Educación de Tunja, es una institución de formación de docentes con un carácter mixto y además, su proyecto educativo y cultural se enmarca en la concepción educativa de la República Liberal.

En primer lugar, al amparo de la Escuela Normal de Varones de Tunja y bajo la orientación del Educador alemán Julius Sieber, se consolidó un importante núcleo de formación de docentes, que gracias a sus desarrollos, dio lugar a que el gobierno nacional, mediante el decreto 1379 de 1934, derivara de este trabajo una de las llamadas Facultades de Educación de los años 30 . Pese a este importante avance, el proceso se vio abruptamente interrumpido con la decisión de suprimir la Facultad de Educación de Tunja para crear la Escuela Normal Superior en Bogotá.

Tal decisión originó la protesta de los habitantes de la región, que de esta manera presenciaban la forma en que el gobierno central les retiraba este importante centro de formación de docentes. Al respecto escribió Javier Ocampo López:

Con motivo del anuncio y la decisión del gobierno nacional para trasladar la facultad de Educación de Tunja a Bogotá. se hizo el primer movimiento estudiantil de protesta, con la simpatía de la ciudadanía de Tunja y Boyacá, contra el centralismo de la capital del país. Los normalistas y todos los establecimientos de educación de Tunja recorrieron las principales calles de la ciudad el 25 de mayo de $1935 .{ }^{4}$

Pese a las expresiones de inconformidad de las gentes del departamento de Boyacá, el traslado de la Facultad de Educación se llevó a cabo.

En segundo lugar. La Escuela Normal Superior se caracterizó por ser un centro de formación de educadores con un carácter mixto, circunstancia que vendría a tener gran relevancia a la luz de las consideraciones morales y educativas de aquellos años. Al comentar el proceso de concentración de las tres Facultades de Educación en una sola institución denominada Escuela Normal Superior, precisó Juan Manuel Ospina que:

La primera consecuencia de esta decisión. que la historia posterior habría de designar como trascendental. fue el establecimiento de hecho de la educación mixta en el país. Al respecto dice el profesor Socarrás: la primera vez que hubo en Colombia enseñanza mixta, fue allí en la época de López, en la Normal Superior. ${ }^{5}$

El tercer elemento para considerar es el proyecto educativo que encarnó la Escuela Normal Superior. El profesor José Francisco Socarrás, quien fuera Rector y uno de los principales ideólogos de la Normal, describió su perfil institucional en los siguientes términos:

La influencia era universal; del criterio de la Escuela Normal francesa de formar científicos, filósofos y gentes de pensamiento, tomamos la orientación

\footnotetext{
4 Javier Ocampo López. Educación, humanismo y ciencia. Historia de las ideas fundamentales en el desarrollo de la Universidad Pedagógica y Tecnológica de Colombia. UPTC. Tunja. Octubre de 1978. Pág. 85.

5 Juan Manuel Ospina. La Escuela Normal Superior: Círculo que se cierra. Boletín Cultural y bibliográfico del Banco de la Republica Bogotá. Vol. 21 . No. 2. 1984. Pág. 7.

Digitalizado por RED ACADEMICA
} 
humanística: y de la Facultad de ciencias de Berlín la orientación científica. Se buscó hacer una síntesis germano-francesa. La relación especial entre la Universidad y la Normal, existente en Francia, de alguna manera se adoptó en Colombia: la universidad actuando en un marco de gran autonomía, abierta a todos para formar la gran cantidad de profesionales que demanda un país en plena expansión y la Escuela Normal como un recinto protegido por el Estado. ${ }^{6}$

En el mismo sentido de su proyecto educativo ha de considerarse que la Normal superior contó con la suerte de que muchos de sus profesores fueron importantes intelectuales que se refugiaron en el país ante los diversos conflictos bélicos que se llevaron a cabo en Europa durante la época. De otra parte, la biblioteca de la Escuela Normal Superior, se constituyó en una de las más completas y variadas del país.

La presencia de estos intelectuales permitió que en el escenario académico nacional se llevara a cabo una apertura hacia nuevas corrientes del pensamiento y de la ciencia. Movimientos como el marxismo, el psicoanálisis, las nuevas doctrinas del derecho público francés, la filosofía del derecho alemán, la filosofía fenomenológica y existencial, antes vedados por conservadurismo y ¿ rutina hicieron su aparición en las aulas. ${ }^{7}$

A modo de conclusión sobre las características de la institución normalista, valga agregar, que el trabajo de Carlos Low y Martha Herrera sobre la Escuela Normal Superior, precisa que:

Las facultades de Educación no conocieron larga vida puesto que al fortalecerse en la década del 30 el predominio del Partido Liberal, éste dio un vuelco a su orientación y se propuso constituir sobre sus bases una propuesta en la que prevaleciera la influencia liberal, a la vez que se fundamentó en un modelo pedagógico de corte laico y liberal que tomaba distancia de la pedagogía católica. Es así como el Proyecto de la Escuela Normal Superior se abrió paso, dentro del entorno conocido como la República Liberal. ${ }^{8}$

\section{La Normal Superior en el marco del conflicto entre dos posturas educativas}

La reforma constitucional agenciada por el gobierno de la revolución en marcha, tuvo como uno de sus ejes centrales la modificación de las relaciones entre el poder civil y la iglesia, planteamiento que necesariamente cerraba el paso al predominio que la iglesia había alcanzado en el manejo y orientación de la educación nacional y que había quedado reconocido como tal en la Constitución del 86 y en el Concordato de 1887.

De otra parte, la reforma de la Universidad llevada a cabo en aquellos años y las características de la Escuela Normal Superior, suscitaron un agitado debate al transgredirse los límites y postulados que la iglesia y sectores tradicionales del país habían concebido para la educación colombiana.

La reforma planteada golpeaba duramente el reconocimiento de la religión católica como oficial, protegida por los poderes del Estado y además. le retiraba la hegemonía

\footnotetext{
${ }_{7}^{6}$ Op. Cit.

7 Jaime Jaramillo Uribe. "El proceso de la educación del Virreinato a la época contemporánea". manual de Historia de Colombia Tomo II. Pág. 334.

${ }^{8}$ Martha Herrera $\vee$ Carlos Low. Los intelectuales y el despertar cultural del siglo. El caso de la Escuela Normal Superior. Una historia reciente y olvidada. U.P.N. Santafé de Bogotá. 1994. Pág. 25. 
sobre la orientación católica de la educación pública, posición que combatió duramente Laureano Gómez:

El precepto constitucional que manda dirigir y organizar la educación pública en concordancia con la religión católica ha sido eliminado y reemplazado por la suprema inspección y vigilancia del Estado (...) la Escuela laica, la Escuela materialista y sin Dios, será la consecuencia inmediata de esa reforma. ${ }^{9}$

Escribe Fernán González que: "cuando se empezaba a discutir la reforma, Monseñor Miguel Ángel Builes, califica la propuesta como una campaña contra Dios y contra la iglesia (...) Builes ataca también el pernicioso sistema de coeducación en la Universidad". ${ }^{10}$ De igual manera, el columnista Ricardo Silva, expresa desde las páginas del diario El Siglo que: 'El Ministerio de Educación adelanta una campaña de manera clandestina y hábil para minar de base la enseñanza cristiana que venía nutriendo las inteligencias de la juventud". ${ }^{11}$

Por su parte, Darío Echandía, explicaba el papel del gobierno en la educación, precisando que: "El liberalismo no va a reivindicarse combatiendo a sus propias masas y arrebatándoles sus ilusiones (...) no van a hacerse escuelas antirreligiosas, pero van a hacerse escuelas. No se va a envenenar al pueblo para una lucha inútil, pero se le va a instruir". ${ }^{12}$

Respecto a estas supuestas diferencias político-religiosas entre liberales y conservadores. Luis Carlos Perea en un interesante estudio sobre la mentalidad de las elites capitalinas, señala que éstas diferencias fueron más bien formales, pues la actitud del Partido Liberal siempre habría de moverse en un doble papel frente a la cuestión religiosa: De una parte sus intentos de reforma y de modernización, de otra, su estricta y cuidadosa observancia de la fe católica. ${ }^{13}$

Otro de los elementos que resulta recurrente en el debate es la conveniencia de la coeducación o educación mixta en el país, pues el papa Pío XI había presentado en diciembre de 1929, la Encíclica Divini Illius Magistri que hacía alguna referencia al respecto y que desde luego era una posición acatada por las jerarquías eclesiásticas nacionales, Uribe Misas comenta la Encíclica señalando que:

La iglesia condena la coeducación como sistema "erróneo y pernicioso a la educación cristiana", el cual está fundamentado según muchos en el naturalismo, negador del pecado original y además según todos los sostenedores de éste método, en una deplorable confusión de ideas que trueca la legítima sociedad humana en una promiscuidad e igualdad niveladora. ${ }^{14}$

Es en el marco de esta controversia donde tiene sus orígenes y desarrollos la Escuela Normal Superior, centro educativo que por efecto de sus características institucionales, también se convertiría en el blanco de algunos de los sectores que participaban en la contienda. Laureano Gómez. escribe en las páginas del diario El Siglo, un artículo

\footnotetext{
${ }^{9}$ Laureano Gómez. El siglo. Febrero 17 de 1936.

${ }^{10}$ Fernán González. Educación y Estado en la historia de Colombia. CINEP. Bogotá. 1978. Págs. 81-82.

${ }^{11}$ Ricardo Silva. La orientación política de la Universidad. El Siglo. Enero22 de 1937.

${ }^{12}$ Molano. Op. Cit. Pág. 72.

${ }^{13}$ Luis Carlos Perea. Porque la sangre es espíritu. Imaginario y discurso político de las elites capitalinas (1942-1949). Aguilar-Santillana. Santafé de Bogotá. Mayo de 1996. Pág. 38.

${ }^{14}$ Alfonso Uribe Misas. La libertad de Enseñanza en Colombia. Bedout. Medellín. Agosto de 1962.Pág. 71. 
denominado El Ministerio de Corrupción Nacional, donde lanza severas críticas sobre las actividades de la Normal, dice que:

...las tesis de grado de la Escuela Normal Superior, encaminadas a adular al Marxismo del personal del Ministerio de Educación; la propaganda comunista que se adelanta en todo el país, con la complacencia del Ministro Echandia y por agentes de dicho funcionario. ${ }^{15}$

De la manera tan vehemente como se atacaba a la Escuela Normal superior y los problemas morales que - según sus contradictores-, ocasionaba la institución, da cuenta un artículo de prensa del año 1941:

El carácter mixto de esta Escuela Normal ha provocado siempre problemas morales de suma gravedad: para la muestra: el señor (AV) alumno de la Escuela de último año, sedujo y deshonró a una de las alumnas (NN) esquivando el matrimonio luego (...) En el mismo año próximo pasado (sic) J.O. vivió prácticamente en concubinato con la alumna S.G. sin que se intentará poner remedió a tamaño escándalo. ${ }^{16}$

José Francisco Socarrás, quien fuera Rector de la Escuela Normal Superior, expresaba $^{17}$ que no era cierto que en la institución se atentará contra las creencias religiosas de los colombianos, que por el contrario se cultivó un clima de tolerancia ideológica entre los maestros y estudiantes, condición esencial de la libertad de aprendizaje sobre la cual se construye una universidad investigativa. Sin embargo, esta actitud académica no se aceptaría sin reservas en el país acostumbrado a la tradicional confesionalidad en la formación de docentes.

La caída de la república liberal, el proceso de disolución de la Escuela Normal Superior y la reorientación de la educación.

Para las elecciones presidenciales de mayo de 1946, el Partido Liberal, que desde 1930 con el mandato de Olaya Herrera se había mantenido en la Presidencia de la República, se presentó con dos candidatos presidenciales (Gabriel Turbay y Jorge Eliecer Gaitán), quienes perdieron las elecciones frente al aspirante Conservador Mariano Ospina Pérez.

Una de las primeras tareas del gobierno de Ospina fue la expedición del decreto 2261 de 1947 que ordenó la reorganización del Ministerio de Educación Nacional, creando entre otros- el Consejo Superior permanente de Educación, los departamentos de educación femenina y de educación normalista, se institucionalizó la enseñanza de la historia oficial y se modificó el escalafón docente de primaria y secundaría, pero ante todo se adelantó la reorientación ideológica del proceso de formación del personal docente. Pues el mismo Ospina señalaba que: siendo la nación colombiana unánimemente católica, a nadie debe extrañar que dentro de la tesis de la libertad de enseñanza imperen en la Escuela la moral cristiana y las orientaciones que emanan de la fe de nuestros mayores. ${ }^{18}$

\footnotetext{
${ }^{15}$ Laureano Gómez. Obras Selectas. 2da. Parte. Colección Pensadores Políticos Colombianos. Cámara de Representantes. Bogotá. (s.f). Pág. 35.

${ }^{16}$ Martha Herrera. Op. Cit. Pág. 123.

${ }^{17}$ Entrevista concedida a Ingrid Muller. La lucha por la cultura. UPN. Santafé de Bogotá. Primera parte. Pág. 140.

${ }^{18}$ Fernán González. Op. Cit. Pág. 103.

Digitalizado por RED ACADEMICA
} 
En 1948 se produce el asesinato del dirigente liberal Jorge Eliecer Gaitán, como es conocido, en Bogotá y otras regiones del país, se produce una serie de levantamientos sociales que por momentos llegó a poner en riesgo el orden establecido. La asonada, que dejó un saldo numeroso de víctimas y de pérdidas materiales, fue objeto de análisis y expresión de los diversos sectores nacionales. Para el caso, resulta de gran interés mencionar la pastoral de Monseñor Miguel Ángel Builes:

Los autores a plazo de la desgracia nacional que estamos padeciendo son dos principalmente: la prensa periódica de la secta y la educación laica y sovietizante (...) otros autores a distancia de tantas desgracias son los legisladores ateos contra los principios religiosos y la enseñanza cristiana y los maestros marxistas que despreciando olímpicamente al episcopado colombiano que protestó contra los desafueros de universidades, colegios y escuelas. Formaron en el materialismo más brutal, durante los últimos 16 años (la República liberal) a estos mismos jóvenes que encabezaron 'a acción demoledora del 9 de abril. ${ }^{19}$

Encontraban aquellos sectores que los desmanes ocurridos en el país, tenían su germen en la educación que habían recibido los educadores y los jóvenes en general , durante el período de la República Liberal. Al respecto, señalan Low y Herrera que: Ios normalistas fueron acusados de subversivos y responsables de la asonada que se presentó en Bogotá. Los estudiantes entraron en huelga y la Normal Superior, al igual que la Nacional, fueron cerradas temporalmente. ${ }^{20}$

Señala Aline Helg que fue: la revuelta popular del 9 de abril en Bogotá la que marcó realmente el viraje de la política educativa colombiana, a través del choque que produjo en los dirigentes conservadores y liberales y en particular en la iglesia católica. ${ }^{21}$ Para el caso de la Escuela Normal Superior, en agosto de 1948, se nombró una comisión para que llevara a cabo la revisión de los reglamentos internos de la institución, punto que parece dar inicio a la serie de decisiones que llevaron a la disolución de la Normal.

Para 1950 llega a la Presidencia de la República Laureano Gómez, cuyo gobierno adelantaría una profunda reorientación ideológica de la educación, dejando por tierra algunas de las gestiones adelantadas por los gobiernos liberales, modificando aspectos como las juntas del escalafón docente, dando mayor participación a la iglesia y a las autoridades municipales en el control de los maestros, separó la educación rural y urbana que en el año 32 había sido unificada y modificó las normas sobre la participación de los estamentos en la dirección de la Universidad, en cuanto los programas se intensificaron las actividades religiosas y se cuidó de permitir la educación mixta.

La reorientación del proceso de formación de los docentes efectuó un papel trascendental durante la administración Gómez y como es apenas lógico, dadas las características y severas críticas que había recibido la Escuela Normal Superior por parte de estos sectores, durante los ahora lejanos días de la República Liberal, no era extraño que la Normal constituyera una prioridad dentro del proceso de contra-reforma educativa.

Para enero de 1951, se expide el decreto 192: "por el cual se adopta el plan de estudios para los institutos de enseñanza pedagógica y se dictan otras disposiciones

\footnotetext{
${ }^{19}$ Miguel Angel Builes. Pastoral del Excmo. Mñor Builes. Et Trabajo. Año III. No. 65. Tunja. Mayo 4 de 1948. Pág. 4.

${ }^{20}$ Martha Herrera. Op. Cit. Pág. 109.

${ }^{21}$ Aline Helg. La educación en Co/ombia 1946-1957 Colección la Nueva Historia de Colombia. Planeta. Bogotá. 1989.Tomo IV. Pág. 113. 
sobre educación normalistas". Este decreto es firmado por Laureano Gómez y para los fines de nuestro estudio conserva una doble importancia: En primer lugar, esta norma establece el programa de estudios -entre otras instituciones- para el Instituto Pedagógico Nacional para Señoritas y en segundo lugar, en este decreto se da el primer paso jurídico para el desmonte de la Escuela Normal superior, pues en su artículo 13 ordena que en adelante, llevará el nombre de Escuela Normal Universitaria. ${ }^{22}$

El proceso de desmonte de la institución normalista continúa su trámite, pues para mayo del mismo año 51, se expide el decreto 1215, donde se dispone que la ahora Escuela Normal Universitaria, pasaría a depender de la Secretaría General del Ministerio de Educación. Acto seguido, el 18 de septiembre se expide el decreto 1955, donde se da la puntada final al Proyecto educativo de la Escuela Normal Superior, pues en el artículo primero del decreto se dispuso que:

La Escuela Normal Universitaria se dividirá en lo sucesivo en sus dos secciones masculina y femenina, así; la primera, se llamará Escuela Normal Superior de Varones y desde el $1^{\circ}$. de enero de 1952 funcionará en el local que ocupa la Escuela Normal de Varones de Tunja; la segunda, en el Instituto Pedagógico Nacional que se eleva a la categoría de Instituto Pedagógico Nacional Superior, y tendrá las características de Escuela Normal Superior Femeinal ${ }^{23}$

Esta decisión, en la práctica ejecutaba lo que ya se veía venir desde el mes de abril de 1951, cuando el Rector Interino de la Escuela Normal: el doctor Antonio Andrade Crispino: manifestaba la voluntad del Ministro de Educación, Rafael Azula Barrera de separar a "las señoritas de los jóvenes", para lo cual pensaba "tomar el Instituto Pedagógico para crear una Escuela Normal Universitaria Femenina". ${ }^{24}$

El historiador Javier Ocampo López, al comentar la disolución y traslado de la Escuela Normal Superior, señala la existencia de causas políticas, morales y regionales, planteamiento que guarda profunda correspondencia con las tres características y circunstancias de creación de la Normal Superior que ya citamos y que definirían las nuevas características y el perfil de la Escuela Normal Universitaria Femenina que años más tarde se convertiría en la Universidad Pedagógica Nacional Femenina. Esta es la razón para que Téllez Iregui, afirmara: que en cierto modo, la Universidad Pedagógica encuentra sus orígenes en un intento tardío por hacer frente a los avances de la política educativa de la revolución en marcha ${ }^{25}$. Desde luego, se trata de un intento tardío, pero no por ello menos efectivo en la reorientación de los procesos de formación del personal docente.

En el terreno político-educativo, la discusión central giraba en torno a orientar los fines de la educación conforme a los dogmas de la religión católica, en el plano moral la inconveniencia de la educación mixta y en el espectro regional, el traslado fue impulsado por el Ministro de Educación Rafael Azula Barrera, natural del Departamento de Boyacá , que de esta manera, le devolvía a su Departamento la Universidad que el centralismo

\footnotetext{
22 Juan Carlos Garzón Barreto. "La Universidad Pedagógica Nacional Femenina. Sus orígenes y consolidación en el marco de la contra-reforma educativa de los años 50". Tesis de pregrado. Universidad Pedagógica Nacional. 1997.

${ }^{23}$ Aracely Cardona La Universidad Pedagógica Nacional: Un estudio sobre su evolución a través de las normas. Documentación Educativa. Vol. 2. No. 3. UPN. Bogotá. 1974.

24 Juan Carlos Garzón. Op. Cit

${ }^{25}$ Gustavo Téllez Iregui. "La Universidad Pedagógica Nacional. Principio y proceso de una reforma" Educación y Cultura. FECODE. No. 7. Bogotá. Abril de 1986. Pág. 34. 
liberal de los años 30 le había arrebatado, justamente para crear la Normal Superior, que ahora desaparecía con el traslado de parte de la institución a la ciudad de Tunja.

Resuelto el problema moral de la educación mixta con la división de la Normal por sexos, resuelto el problema de reparar las molestias ocasionadas a los intereses regionales, quedaba por ejecutarse la tarea de reorientar hacia los fueros católicos y patrióticos la formación del personal docente, aspecto en el cual los inspiradores de la reforma no fueron menos diligentes.

Lisandro Medrano, Director del Departamento de Normales del Ministerio de Educación Nacional y quien años más tarde sería profesor de la Universidad Pedagógica Nacional femenina, explicaba el espíritu y las nuevas intencionalidades en la formación de los educadores.

Desde la Dirección de normales se ha recomendado que no se haga desde la cátedra campaña proselitista y que se abstengan los profesores de envenenar la mente de los educadores con teorías disolventes ajenas a nuestra cultura cristiana y huérfanas deespiritualismo (...) Hemos procurado que el trabajo que se desarrolla en las normales sea un trabajo intencionado, un trabajar para algo. No nos conformamos con enseñar por enseñar y aprender por aprender. Queremos enseñar para algo, para cimentar las grandes verdades religiosas y patrióticas. Queremos que nuestros futuros maestros aprendan para algo: para vivir una vida puramente cristiana, una vida que conjugue las grandes virtudes de caridad, justicia y solidaridad. ${ }^{26}$

El Ministro de Educación Nacional, Rafael Azula Barrera, dedica una parte de su informe al Congreso Nacional, para precisar una vez más las nuevas finalidades educativas en la formación de los maestros:

El gobierno actual ha acometido con toda decisión la tarea de atender a este verdadero frente de la defensa nacional (...) El gobierno ha prospectado su acción educativa no sobre planos efímeros sino sobre bases perdurables, colocando el ramo normalista en primera línea convencido de que, ante todo, la formación y transformación del espíritu de los educadores es lo que necesita el país para cumplir con esta cruzada redentora. La educación se había desviado por peligrosos senderos materialistas y es indispensable y urgente restaurar la esencia cristiana de su formación. ${ }^{27}$

Roberto Pineda Giraldo, egresado de la Escuela Normal Superior, al referirse a los efectos de la disolución de la Institución, señala que: se mató todo un sistema educativo, un modo filosófico de encarar la pedagogía en relación con la ciencia y la investigación. ${ }^{28}$

\section{La puesta en funcionamiento de la Escuela Normal Universitaria Femenina}

La Escuela Normal Universitaria Femenina inició labores haciendo uso de los elementos e instalaciones del Instituto Pedagógico Nacional para señoritas, que desde 1927 había funcionado en el local de la Avenida Chile, pues la mayor parte del mobiliario de la Escuela Normal Superior fue enviado a la ciudad de Tunja.

\footnotetext{
${ }^{26}$ Yvon Lebot. Educación e ideología en Colombia. Bogotá. 1985. Págs. 35-36.

${ }^{27}$ Rafael Azula Barrera. Memoria del Ministro al Congreso. Editorial lqueima. Bogotá. 1951.

${ }^{28}$ Martha Herrera y Carlos Low "Roberto Pineda Giraldo: 40 años de antropología colombiana" Revista Colombiana de Educación. No. 20. CIUP-UPN. 1989. Pág. 20). 
Para llevar a cabo la dirección de la nueva institución el gobierno nacional contrato un grupo de educadoras alemanas (Marlene Mies en Filosofía y Psicología, Elizabeth Schader en Biología y química, Alwine Stoffel en idiomas) encabezadas por la doctora Franziska Radke, educadora que impulsó la consolidación del Instituto Pedagógico, pero que se había marchado del país durante los años de la llamada República Liberal.

Respecto al regreso de la doctora. Franziska Radke al país, Victoria Bossio, quien fuera docente de la Escuela Normal Universitaria Femenina, señaló que:

Nunca me pude explicar por qué volvieron a traer a la doctora Radke, ya que la Normal Superior había dejado un gran número de profesionales que habían podido ser Rectores de la Escuela Normal Universitaria Femenina. En esto culpo al Presidente Laureano Gómez y al jefe de normales Vicente Castellanos, quien fue el que realmente convenció a esta doctora, haciendo un viaje exclusivamente para ir a traerla. ${ }^{29}$

La razón de volver a traer a la doctora Radke al país, quizá se comprenda con mayor claridad, si tenemos en cuenta que fruto de una serie de diferencias que tuviera la profesora Victoria Bossio con la educadora alemana acerca de la Dirección del Instituto Pedagógico, la Señora Radke expresara con absoluta claridad su disposición de contribuir cabalmente con la misión que le había encomendado el gobierno nacional

Lo que me interesa exclusivamente es poder trabajar y con éxito. Cuando las directoras tratan de impedirme en eso, obstaculizan al mismo tiempo las intenciones del gobierno conservador que me trajo por segunda vez y al cual yo quiero servir lealmente y con todas mis fuerzas.

Para el año en que se puso en marcha la Normal Femenina contó con un grupo de 32 docentes, de los cuales señalaba Franziska Radke, habian sido cuidadosamente escogidos bajo la orientación de Vicente Castellanos. Respecto a este primer grupo de educadores podemos observar, que de un lado se trata de algunas personas provenientes de la Normal Superior, como: Estiliano Acosta, Monseñor José Joaquín Elorza, Rudolf Hommes, Carlos Páez Pérez y Rafael Maya. De otra parte, figuran algunas docentes que se habían formado con Franziska Radke, en la época en que aquélla dirigió el Instituto Pedagógico.

Paralelo a la selección de los docentes. la señora Radke insistió permanentemente ante el gobierno central para que se acometiera la reparación del antiguo local del Instituto Pedagógico y de sus escuelas anexas. Para resolver este problema el gobierno de Gómez llevó a cabo la construcción de un moderno edificio con destino a la Escuela Normal Universitaria Femenina.

En relación con los programas académicos. La Normal Femenina adoptó los mismos programas que había ofrecido la Normal Superior, a saber: ciencias biológicas y químicas, ciencias físicas y matemáticas, ciencias sociales y económicas, ciencias de la educación y filología e idiomas. Fruto de los desarrollos de la institución para 1954 se logró consolidar los primeros planes propios. ${ }^{31}$ Estos planes se caracterizaron de un lado, por los

\footnotetext{
${ }^{29}$ Berenice Pava. "La doctora Radke en Colombia". Maestría en Historia de la Educación. Fotocopiado. UPN. Santafé de Bogotá. 1997.

30 Archivo universitario UPN. Archivo de Rectoría. "Memorandum de la Rectora de la Escuela Normal Universitaria Femenina sobre la Dirección del Instituto Pedagógico .Nacional". 1952.

${ }^{31}$ Archivo Universitario UPN. Archivo de Rectoría. 1952.

Digitalizado por RED ACADEMICA
} 
contenidos y actividades religiosas y de otra parte, en la importancia que adquirió la práctica docente adelantada en las instituciones anexas a la Normal.

En un memorándum de 1954, elaborado por la doctora Radke, ésta justifica la instalación del oratorio diciendo que: las estudiantes que se gradúan en ella, desempeñarán puestos en que su formación religiosa será la base del trabajo. Por eso la Universidad Pedagógica Femenina no puede transmitir solamente conocimientos filosófico-religiosos, sino ha de formar al estudiantado en las prácticas religiosas.

Otra de las materias a destacar fue la llamada "Cátedra Bolivariana", que se había establecido en 1952 y que en carta dirigida por Horacio Bejarano a la señora Radke, la manifiesta que el gobierno está interesado en que:

En el primer año de cualquier facultad del país se estudiará el pensamiento filosófico-político del Libertador a través de sus proclamas, cartas y discursos (...) El gobierno nacional está interesado en difundir entre la juventud el glorioso ideario cristiano y nacionalista del Libertador. Es inaceptable que nuestros estudiantes aprendan a analizar las tesis de Smith y de Marx, y desconozcan las líneas fundamentales del pensamiento de Bolívar acerca del gobierno de los pueblos americanos. ${ }^{32}$

Las estudiantes de la Normal Femenina, para julio de 1952. constituyen un grupo de 107 alumnas becadas (con noventa pesos mensuales) directamente desde el Ministerio de Educación, por medio de resolución, donde resulta curioso apreciar que por lo menos 35 de ellas recibieron su beca en fechas anteriores a la creación misma de la Normal. Las alumnas, al igual que las estudiantes del Instituto Pedagógico permanecieron en la Normal bajo la modalidad de internado, para lo cual, recibió entre otros, el apoyo de las residencias estudiantiles de las comunidades religiosas.

La creación de la Universidad Pedagógica de Colombia en Tunja y la reorganización de la Escuela Normal Universitaria Femenina.

A mediados del año 1953 el gobierno de Gómez-Urdaneta entra en crisis y la situación política del país lleva a que el 13 de junio asuma el poder el General boyacense, Gustavo Rojas Pinilla.

Una de las tareas emprendidas por Rojas fue la expedición del decreto 2655 del 10 de octubre de 1953, mediante el cual se crea la Universidad Pedagógica de Colombia con sede en Tunja. Esta norma habría de generar un intrincado proceso jurídico que afectaría el funcionamiento de la Escuela Normal Universitaria Femenina, hasta desencadenar en la creación de la Universidad Pedagógica Nacional Femenina. Veamos:

En efecto, aquel decreto no sólo creo la Universidad en Tunja, sino que en su artículo segundo dispuso que a esta nueva institución se le: incorporan las facultades, institutos y demás dependencias que actualmente integran las Escuelas Normales Superiores Universitarias de Tunja y Bogotá, así como, los establecimientos que se crean y anexan por medio de estas disposiciones. ${ }^{33}$

Esta decisión, en la práctica daba lugar a varias situaciones: en primer término, La Escuela Normal Universitaria Femenina de Bogotá, el Instituto Pedagógico Nacional y sus

\footnotetext{
${ }^{32}$ Ibid. 1955.

${ }^{33}$ Araceli Cardona. Op. Cit. Pag. 32.

Digitalizado por RED ACADEMICA
} 
instituciones anexas, que venían funcionando bajo la dirección autónoma de la doctora Franziska Radke, pasaban a formar parte de la Universidad Pedagógica de Colombia con sede en Tunja. En segundo lugar, La Normal Femenina de Bogotá, pasaría a llamarse Sección Femenina de la Universidad Pedagógica de Colombia y por último su actual Rectora continuaría en el cargo con el carácter de Directora de la Sección Femenina.

En términos generales, la norma citada dificultaba los diversos procesos administrativos, entre ellos, la contratación de los docentes en la ahora Sección Femenina, pues pese a que el articulado del decreto creo un Consejo Directivo para la Sección Femenina, la autonomía de la institución se perdió, pues también se dispuso establecer un Consejo Directivo General en Tunja, del cual hacía parte la doctora Radke.

La marcada separación de las dos secciones se dificultaba por las condiciones de desplazamiento para entonces existentes en el país, generando el distanciamiento entre la doctora Radke y Rector de la Universidad en Tunja, Julius Sieber, quien en carta dirigida a su paisana buscaba suavizar las relaciones:

Como Rector de la Universidad, espero su colaboración más decidida, ya que la tarea a realizar es gigantesca y sólo a base de una cumplida colaboración, ausente de reticencias y de reservas de cualquier índole en general, es posible dar a la empresa que se entregó a nuestras manos una consolidación inicial. ${ }^{34}$

En medio de las complejas relaciones administrativas que se habían tejido entre las dos secciones de la Universidad, transcurridos cinco meses de trabajo conjunto, el gobierno expidió el decreto 547 del 23 de febrero de 1954, donde dispuso que la Sección Femenina de la Universidad Pedagógica de Colombia funcionara hasta el 31 de diciembre de 1955, bajo el mismo régimen que había venido sometida antes de la expedición del decreto 2655 del 10 de octubre de 1953 y que durante este lapso la Directora de dicha sección no formara parte del Consejo Directivo de la Universidad Pedagógica de Colombia. En términos sencillos, esta decisión significaba que la Sección Femenina volvía a tener su carácter de Escuela Normal Universitaria Femenina, pues su régimen anterior era el estipulado en el decreto 1955 del 18 de septiembre de 1951.

No alcanzaron a transcurrir tres meses y el gobierno nacional expidió el decreto 1423 del 4 de mayo de 1954, donde reglamenta los órganos directivos de la Universidad Pedagógica de Colombia, estableciendo tres Consejos: un Consejo General para toda la Universidad, donde dice participarán los Rectores de la sección masculina de Tunja y de la sección femenina de Bogotá. Esta norma vuelve a unificar de manera expresa las dos secciones, que habían sido divididas al regresarlas al régimen que tenían antes de la creación de la Universidad Pedagógica de Colombia, pero no hace referencia o explica dónde quedan los efectos de la decisión de separarlas hasta diciembre de 1955.

Prácticamente un año después que la institución permaneciera en el limbo jurídico, el 2 de marzo de 1955, se produjo la expedición del decreto 499, que volvió a crear el Consejo Directivo de la Universidad Pedagógica de Colombia. En uno de los considerandos de este decreto, se dice que la norma se expide: considerando que mediante el decreto 547, se crea la Universidad Pedagógica Independiente. Al examinar detenidamente el texto de las normas en cuestión no es muy difícil apreciar que, en primer lugar, el tal decreto 547 había vuelto la Sección Femenina a su anterior régimen, pero no había creado ninguna Universidad Pedagógica Independiente, es más, como ya lo

\footnotetext{
${ }^{34}$ Archivo Universitario UPN. Archivo de Rectoría. Correspondencia recibida 1952-1965.

Digitalizado por RED ACADEMICA
} 
afirmábamos, después se expidió una norma que expresamente sugería la reunificación de las dos secciones de la Universidad Pedagógica de Colombia.

A estas alturas, era tan complejo e intrincado el enredo jurídico que había armado el legislador en el proceso de consolidación de estas instituciones de formación de educadores, que los redactores del decreto 499 del 2 de marzo de 1955, que venimos comentando, no sólo cometieron el error que acabamos de señalar, sino que aún más, ignoraron que hacía un mes, justamente el 10 de febrero, el General Gustavo Rojas Pinilla, había expedido el decreto 197. en cuyo primer artículo se había creado la UNIVERSIDAD PEDAGÓGICA NACIONAL FEMENINA.

Con motivo de la expedición del decreto que creo la Universidad Pedagógica Femenina, la doctora Radke manifestó en una entrevista para televisión que:

El hecho es un acontecimiento de importancia trascendental para la institución, ella es la única entidad femenina, exclusivamente educativa del país a la cual se ha confiado la libertad de obtener un fin meramente intelectual por la forma adecuada a su modo especial de pensar. La generosidad del Señor Presidente (Rojas Pinilla), es sin precedentes en la historia de la educación femenina del país. ${ }^{35}$

La decisión es sin precedentes, si consideramos que para la época la Universidad Pedagógica Nacional Femenina, es la única universidad pública del país que tiene un carácter exclusivamente femenino, cuando en el país ya se había ensayado y con éxito la educación mixta. La puesta en marcha de un centro universitario femenino para la formación del personal docente, significa la coronación de las intencionalidades de los sectores tradicionales que paso a paso echaron atrás el proyecto de formación de docentes que habían acuñado los gobiernos de la República Liberal. Sin soslayar en manera alguna los valiosos aportes que haría la Universidad Pedagógica Nacional Femenina en el proceso de institucionalización de la formación del personal docente en el país, nos resulta categórico tener que afirmar, que evidentemente la institución encuentra parte de sus orígenes en el marco de una contra-reforma educativa.

La expedición del decreto 197 de 1955, no sólo creó la Universidad Pedagógica Nacional Femenina, sino que en otra parte de su articulado, previó la creación de su Consejo Directivo, integrado por el Secretario del Ministro, la Rectora de la Universidad, un representante elegido por los profesores y la alumna de último año que tuviera las más altas calificaciones. A este Consejo se encomendó la tarea de elaborar los primeros Estatutos de la Universidad. ordenamiento que se desarrolló durante el año 1956, y cuya reglamentación precisó entre otras cosas: los Consejos Directivo y Académico, las calidades de la Rectora y los Decanos. Los procesos de matrícula, asistencia a clase, los exámenes, las prácticas docentes, las sanciones, se designó a Santa Teresa de Jesús como patrona de la Universidad.

El texto del Estatuto se inspira en el espíritu e intencionalidades de la contra-reforma que ya nos encargamos de examinar ampliamente. En la parte inicial se señala que la Universidad de acuerdo con sus fines comprenderá todos los grados de la educación femenina, y así lo era, pues en un memorando del año 55, la señora Radke ofrece el siguiente panorama de la institución:

\footnotetext{
${ }^{35}$ Archivo universitario UPN Archivo de Rectoría. Marzo 8 de 1955.

Digitalizado por RED ACADEMICA
} 
La Universidad misma tenía 170 alumnas, el Instituto de Bachillerato 200 alumnas, el Instituto de Educación Preescolar 80 alumnas, el Kindergarten 150 alumnas, el Instituto Pedagógico 250 alumnas, la Escuela Anexa (de la calle 73) 800 alumnas, la Escuela Anexa de Prácticas Docentes 200 alumnas, la Escuela Anexa EI Nogal 200 alumnas, para un total de 2.050 alumnas a cargo de la Institución. ${ }^{36}$

La importancia y el papel preponderante que alcanzaría la Universidad Pedagógica Nacional Femenina en la formación del personal docente, se comprende con mayor facilidad, si consideramos que desde comienzos de la década del 50, la Misión Lauchin Currie planteó la necesidad de mejorar las condiciones de la carrera del magisterio para estimular la selección de la profesion docente por parte de los jóvenes, pues una de las principales necesidades era formar de manera urgente los educadores que el país requería.

Para 1956, se estima que de 24.579 maestros en ejercicio, 16.728 no tienen grado; 748 son bachilleres, 2.747 son normalistas elementales y 4.356 son normalistas superiores

Respecto a las normales del país que también formaban educadores; para este mismo período existen 98 instituciones, donde un ligero examen de la formación de sus profesores, arroja que sólo 64 son licenciados y 134 son maestros bachilleres. Al revisar el número de maestros que se forman en estas normales (98) por año, en el periodo 1955-1956, en su conjunto llegan a una cifra de 178 normalistas, lo que indica que en promedio no alcanzan a formar dos normalistas por año. En el conjunto de la educación superior, existen 24 Universidades, con 94 Facultades y 15 Institutos y Escuelas para quienes ya adelantaron la segunda enseñanza (bachillerato). Estas universidades se pueden clasificar como tres (3) de carácter nacional, nueve (9) departamentales y doce (12) universidades privadas; instituciones donde la única femenina es la pedagógica de la Avenida Chile. ${ }^{37}$

Bajo la orientación de la doctora Radke, la Universidad continúa su proceso de consolidación institucional hasta el mes de mayo de 1957, pues 12 días después de la caída del General Rojas Pinilla y el establecimiento de la Junta Militar de Gobierno, el diario El Tiempo daba cuenta del inicio de una huelga estudiantil en la Universidad Pedagógica Nacional Femenina, primer movimiento estudiantil que registra la Universidad en su historia y que conduciría a que la señora Radke y algunos de los profesores alemanes que le acompañaban renunciaran a sus cargos. Independientemente del proyecto político-educativo que agenciaron de manera consciente o inconsciente, el personal docente alemán contribuyó de manera efectiva a la consolidación de una de las principales instituciones de formación de educadores del país.

Con el apoyo de algunos profesores de la Universidad, las estudiantes establecieron un comité de huelga que fue respaldado por estudiantes de otras universidades ligados a la Unión Nacional de Estudiantes Colombianos (UNEC). Las universitarias presentaron al Ministro de Educación, Próspero Carbonell, un pliego de peticiones de 13 puntos: donde solicitaban entre otras cosas: la salida de la señora Radke, reforma de los programas, mayor participación y buen trato a profesores y estudiantes, mejoramiento salarial de los docentes, dotación de biblioteca y algunos laboratorios ${ }^{38}$

\footnotetext{
${ }^{36}$ Archivo universitario UPN. Archivo de Rectoría. 1955.

${ }^{37}$ Gabriel Betancur Mejía. Documentos para la historia del planeamiento integral de la Educación. UPN. Vol. 1. Bogotá. 1984. Pág. 173.

38 Una recopilación más detallada de este movimiento estudiantil aparece en el trabajo de grado sobre la Universidad Pedagógica Nacional Femenina que ya citamos. 
Luego de la salida del personal alemán, la dirección de la Universidad fue ocupada por Sara Noriega Balleteros. Genara Moreno Peñaranda, e Irene Jara de Solórzano, educadoras que habían estado ligadas a las instituciones que le dieron origen a la Universidad Pedagógica y que ocuparían importantes cargos en el sector educativo.

Puesto que la Universidad tenía en su conjunto de instituciones los diversos grados, las estudiantes pasaban de la Anexa al Instituto Pedagógico y de éste a la Universidad. Una vez culminados sus estudios salían a especializarse al exterior, otras ingresaban como profesoras de las instituciones anexas a la Universidad o a la cátedra universitaria. Este es el origen del primer capital académico que con personal colombiano atesoró la Universidad Pedagógica. Personal docente, del cual en su informe al Congreso Nacional, el Ministro de Educación Gonzalo Vargas, no dudaría en señalar que:

Los profesores de la Universidad Pedagógica Nacional Femenina pertenecen al magisterio más idóneo con que cuenta el país. La mayoría ha hecho cursos de especialización en el exterior, ha seguido seminarios internacionales en sus respectivos campos, y muchos son considerados como valores dentro del patrimonio cultural de Colombia.

A nivel general, la Universidad Pedagógica Nacional Femenina y la Normal Femenina de la cual surgió, le entregaron al país, 375 educadoras en el periodo comprendido entre 1953 y 1962, fecha hasta la cual la Universidad se denominó femenina, pues el decreto 2188 de 1962, determinó que en adelante se Ilamaría simplemente Universidad Pedagógica Nacional. La Universidad en su etapa femenina graduó 41 profesionales por año, cifra que en su conjunto duplicó el número de licenciadas que había formado la Escuela Normal Superior en el periodo 1939-1952.

De esta manera, la institución aparte de sus desarrollos internos, fue ganando a través de sus egresados una presencia permanente en el seno de la Escuela y la sociedad. Presencia que reconocen inclusive desde apartadas regiones del país, pues en carta enviada a la institución desde la ciudad de Cartagena por un padre de familia, entre líneas simplemente se concluye: la Universidad Pedagógica (..) Un plantel que es orgullo de Colombia. 